OnLine Journal of Biological Sciences 11 (1): 18-22, 2011

ISSN 1608-4217

(C) 2011 Science Publications

\title{
Enhancing Bioconversion Efficiency of the Earthworm Eudrilus Eugeniae (Kingberg) by Fortifying the Filtermud Vermibed using an Organic Nutrient
}

\author{
${ }^{1}$ K. Vasanthi, ${ }^{2}$ K. Chairman, ${ }^{2}$ J. Savarimuthu Michael, \\ ${ }^{2}$ A. Kalirajan and ${ }^{2}$ A.J.A. Ranjit Singh \\ ${ }^{1}$ Department of Zoology, Sri Parasakthi College for Women, Courtallam, \\ ${ }^{2}$ Department of Zoology Sri Paramakalyani College, Alwarkurichi, \\ M.S. University, Tirunelveli,TamilNadu, India
}

\begin{abstract}
Problem statement: Rapid urbanization and population growth are largely responsible for very high increasing rate of solid waste in the urban areas, its proper management and recycling is major problems of Municipal Corporation. Conversion of industrial wastes in to beneficial vermicompost not only solves solid waste accumulation but also yield highly nutritive organic manure. Approach: Enhancing the efficiency of earthworm that is involved in process of converting sugar mill filter press mud in to vermicompost, will be highly economical. An African earthworm Eudrilus eugeniae was used to convert the sugar mill filter press mud into nutritive vermicompost. To enhance vermicomposting efficiency, an organic nutrient preparation Jeevamirtham, an effective microbial suspension was supplemented. Results: The vermicompost yielded in Jeevamirtham supplemented vermibed had a significantly high nitrogen, phosphorus and micronutrient value. In the Jeeamirtham supplemeted vermicompost $\mathrm{C} / \mathrm{N}$ ratio was $55.5 \%$ higher than that was present in the cowdung added vermicompost. In filtermud-Jeevamirtham, vermibed the mean egg production by a single worm at 45 days of growth was $12 \pm 2.6(33.33 \%)$. Jeevamirtham had influenced the egg production. When compared to filtermud-cowdung vermibed reared worm, $(77.4 \%)$ the hatchability of eggs in filtermud jeevamirtham vermibed was high $(85.8 \%)$. This indicates that the jeevamirtham supplementation strengthens viability of the eggs. Conclusion: The present study recommends utilization of effective microorganism suspension, Jeevamirtham for vermicomposting to enhance the functioning of the earthworm and to increase fertilizer value of vermicompost. In the present study also macronutrient and micronutrient content increased significantly in vermicompost prepared from pressmud waste due to the supplementation of Jeevamirtham. This is practical significance if adopted by urban farmers as a result of soil health and in turn the productivity of soil can be maintained for further agriculture.
\end{abstract}

Key words: Filterpressmud wastes, eudrilus eugeniae, jeevamirtham vermibed, micronutrient value, present study, recommends utilization, microorganism suspension, organic nutrient, vermicomposting process

\section{INTRODUCTION}

The vermicomposting process is a result of the combined action of the earthworms and microflora living in earthworm intestines and in the growth medium. Vermicompost improve the soil structure, increasing the water holding capacity and porosity which facilitate the root respiration and growth (Lee, 1992). The beneficial effects of vermicompost on crops like maize (Gutierrez-Miceli et al., 2008), wheat (Sharma and Madan, 1988), strawberry (Singh et al.,
2008), petunias (Arancon et al., 2004), marigold, pepper, cornflower, tomato (Bachman and Metzger, 2008), blackgram and pepper (Arancon et al., 2004). Recycling of wastes through vermicomposting reduces problems of disposal of agricultural as well as industrial wastes without adversely impacting the environment (Prakash and Karmegam, 2010)

Filter cake or Pressmud as it is commonly known is one of the important by-products of the sugar industry. Filterpressmud is a soft, spongyamorphous and dark brown to brownish white material containing sugar,

Corresponding Author: A.J.A. Ranjit Singh, Department of Zoology Sri Paramakalyani College, Alwarkurichi,

M.S. University, Tirunelveli,TamilNadu, India 
fibre coagulated colloids including cane wax, albuminoids, inorganic salts and soil particles. It is readily converted to a repository of macro and micro nutrients besides being a very effective soil ameliorant thorough vermicomposting. Pressmud mounts as it is accumulated at a stocking point, it undergoes self combustion and adds to pollution of the environment besides causing an eyes sore (Lakshmi and Vijayalakshmi, 2000). According to curing of Pressmud for 4-6 weeks is necessary before application to the soils. Hence, the present work was undertaken to convert fresh filter Pressmud into nutrient rich manure by using African Earthworm Eudrilus eugeniae (Kinberg)

According to proximately 12 million tones of press mud is produced in India annually. Due to the prohibitive cost of sludge disposal, it is either dumped in open or along roadsides or railway tracks or stored in the sugar mill premises where it causes adverse impacts on the ambient environment (Parthasarthi, 2008).

Conventional composting of press mud takes about 6 months and also does not remove the foul odor completely. Vermicompost so obtained has less nutritive value and more compactness. Therefore, appropriate press mud management technology is desired which not only protect and conserve the environment and land resources but also to recover the nutrients present in it. The present study deals with the vermiconversion of filterpressmud waste using a natural nutrient preparation, Jeevamirtham into nutrient rich manure by using the earthworm Eudrilus eugeniae.

\section{MATERIALS AND METHODS}

Jeevamirtham preparation: Two hundred litres of water was taken as a stock solution. To which, the following ingredients were mixed:

- Ten $\mathrm{Kg}$ desi cowdung (Cow dung of the native Indian breed cow, collected fresh)

- $\quad$ Five to Ten litres of desi cow's urine. (Urine can be collected and stored for any number of days, does not lose quality)

- Two Kg of Palmyra jaggery and 2-4 L of sugar cane juice

- Flour of black gram - best if hand ground; not as effective if ground in a power grinders the particle size varies

- Handful of chemical free soil

First the cow dung and urine were added to water, then jaggery, flour and soil were added together to that solution content was stirred clockwise for couple of minutes and this was done 3 times a day. The solution fermented, within 48-72 h. The solution was stored in protective sterile containers.

Earthworm's cultures: E.eugeniae was obtained from a vermicomposting unit of Kalapavirusam in Tenkasi, Tamilnadu (India). The stock culture of the earthworm was maintained in plastic containers using partially decomposed bio-waste and cowdung as growth medium in laboratory condition. This was further used in the vermicomposting experiment.

Filtermud: The filter mud was collected from the Dharani Sugar Factory near Vasudevanallur, during June 2010. Fresh filter mud was kept in shade for 2-3 weeks before using for the vermicomposting process (Sangwan et al., 2008). The shade dried filterpressmud was then blended with organic growth promoter Jeevamirtham rich in microbes and used as a bulking agent to increase the $\mathrm{C} / \mathrm{N}$ ratio. The mixture was prepared by mixing $200 \mathrm{~mL}$ of $200 \mathrm{~g}$ cow dung and $1000 \mathrm{~kg}$ filter mud, the raw material for the vermicomposting process. Before starting of the experiment, Filterpressmud wastes (FM) and the filterpressmud wastes with Jeevamirtham (FM+JM) and Filterpressmud with cowdung mixture (FM+CD) were pre-composted for 15 days so that it becomes palatable to the earthworms.

Experimental design: The vermibeds were prepared using filterpressmud in plastic containers and watering was done regularly to moist the medium. Three treatments were taken for vermicomposting of FM materials; one with cowdung alone; while the other two with a mixture of Filterpressmud and Jeevamirtham and Filterpressmud and cow dung. The plastic containers were filled with $1.5 \mathrm{~cm}$ thick sterilized soil layer at the bottom as soil is considered as an important supporting material for vermicomposting (Yadav et al., 2010), Control and treatments were triplicate.

To each plastic container, 10 adult 40 days old earthworms Eudrilus eugeniae were introduced from the stock culture after pre-composting of the raw materials. The experiment was conducted in dark room in ambient temperature. The moisture levels in the experimental containers were maintained at $70 \pm 10 \%$ (Yadav and Garg, 2009).

The vermicompost was harvested after the appearance of black granular structure on the surface of the composting medium. Watering of the composting medium was discontinued four days before the harvesting. Vermicompost output from each treatment was calculated on dry weight basis. Population of earthworm and their biomass as well as cocoons were 
measured at the end of the experiment as per the method given by Gupta and Garg (2008).

Growth and reproduction of worm: After an undisturbed 7 days of composting period, the content in the triplicates was mixed and moisture content was checked together with earth worm's activity. Every 15 days over a period of 45 days the worms were hand sorted and weighed.The weight of 10 worms were taken together $(\mathrm{mg})$ and calculated to percent of single worm weight. The Cocoons production by earthworm was measured in each worm worked compost containers. Separated cocoons were counted and introduced into separate bedding containing the same material in which their parents were reared. On the basis of the obtained data about the biomass and cocoon numbers, other parameters of earthworm such as biomass increase rate $\left(\mathrm{mg} \mathrm{day}^{-1}\right)$, maximum weight achieved and reproduction rate (cocoon/worm/day) were calculated with the help of the recorded data for different worm.

Characteristics of the composts: After 45 days, worms were removed from the Worm-worked compost (WC). Samples of Worm-worked compost (WC) and control compost were sun dried and analyzed for $\mathrm{pH}$ (1:2.5 soil water suspension), electrical conductivity (EC) $(1: 2.5$ soil water suspension filtrate), organic carbon (OC).

Statistical analysis: Paired sample t-test was used to analyze the differences in vermicompost production in different treatments. The same test was used to compare the mean values of different chemical parameters of the compost (control) and vermicompost generated in the two treatments. Finally, one-way ANOVA was employed to compare the effects of the different amendments effects within the control and experimental compost.

\section{RESULTS}

Filtermud is a sugar factory wastes which can't be directly applied to farms. Filter is converted into a nutrient rich vermicompost by employing the earthworm Eudrilus eugeniae. To enhance the bioconversion efficiencies of the earthworm an organic nutrient enriched with effective microbial suspension, jeevamirtham and cow dung were used.

Growth of earthworms: In the present experiments the African earthworm Eudrilus eugeniae was used to convert filtermud into vermicompost. To rear the worm's two types of vermibeds were used. In the both the vermibeds filtermud was used but nutrient supplementation was different. In the filtermudcowdung and filtermud-Jeevamirtham vermibeds the growth of earthworm different. After 45 days the mean weight increase of the earthworm in the filtermudcowdung vermibed was $704.22 \pm 59.62 \mathrm{mg}(94.26 \%$ but in filtermud-Jeevamirtham vermibed the mean weight increase was $803.32 \pm 91.40$ (145.18\%) (Table 1).

Significant difference was noticed in the weight of the earthworm reared in filtermud jeevamirtham vermibed when compared to filtermud-cow dung vermibed. The influence of jeevamirtham to enhance the growth of worm is evident.

Hatching and cocoon production: Cocoon production and their hatchability are influenced by the type of vermibed in which the worms are reared. In the filtermud-cowdung vermibed the mean number of eggs produced by a worm after 45 days of growth was $9 \pm 3$. However in filtermud-Jeevamirtham, vermibed the mean egg production by a single worm at 45 days of growth was $12 \pm 2.6 \quad(33.33 \%)$. Jeevamirtham had influenced the egg production. When compared to filtermud-cowdung vermibed reared worm, (77.4\%) the hatchability of eggs in the filtermud jeevamirtham vermibed was high $(85.8 \%)$. This indicates that the jeevamirtham supplementation strengthens the viability of the eggs (Table 2).

Jeevamirtham mixed vermibed both the cocoons production and hatchling numbers were significantly higher than the vermibed in which cowdung was applied (Table 2).

In the present experiment, the influence of organic nutrient supplement, Jeevamirtham to convert sugar factory filtermud into high quality vermicompost was studied. Further, whether the Jeevamirtham addition with filtermud can influence the economic characteristics of the earthworm was also studied. The efficacy of Jeevamirtham on the vermicomposting efficiency of the earthworm Eudrilus eugeniae was compared with filtermud that was converted into vermicompost by mixing cowdung.

The influence of Jeevamirtham on the physicochemical characteristics of vermicompost was analyzed and compared with vermin bed where cowdung was alone used. The characteristics like pH, EC, N, P, K, $\mathrm{Ca}, \mathrm{Mg}, \mathrm{S}$ and $\mathrm{C} / \mathrm{N}$ ratio in raw filter pressmud, vermicompost made from filter pressmud by supplementing Jeevamirtham and cowdung showed that the various physico-chemical characteristics, in the Jeevamirtham used vermicompost was significantly greater when compared cowdung used vermibed and raw filter pressmud. $\mathrm{N}, \mathrm{P}, \mathrm{K}$ and micronutrients like $\mathrm{Ca}$, $\mathrm{Mg}$ and $\mathrm{S}$ were found at an elevated level in Jeevamirtham mixed vermicompost (Table 3 ). 
OnLine J. Biol. Sci., 11 (1): 18-22, 2011

Table 1: Influence of Jeevamirtham on the growth of the earthworm Eudrilus eugeniae in different vermibeds

\begin{tabular}{lll}
\hline Types of vermibeds & $\begin{array}{l}\text { Initial weight }(\mathrm{mg}) \text { of the earth } \\
\text { worm }(\text { Mean } \pm \text { SD of } 10 \text { worms })\end{array}$ & $\begin{array}{l}\text { Weight of the earthworm (mg) after of } \\
10 \text { worms) (Mean } \pm \text { SD of } 10 \text { worms) }\end{array}$ \\
\hline Filterpressmud + jeevamirtham & $311.04 \pm 0.34$ & $704.22 \pm 59.62(94.26 \%)$ \\
Filterpressmud + cowdung & $327.64 \pm 44.59$ & $803.32 \pm 91.40(145.18 \%)$ \\
\hline
\end{tabular}

Table 2: Influence of Jeevamirutham on cocoon, hatchability and Natality of the earthworm Eudrilus eugeniae employed in the vermicomposting process of Filterpressmud

\begin{tabular}{lllll}
\hline $\begin{array}{l}\text { Types of } \\
\text { vermibeds }\end{array}$ & $\begin{array}{l}\text { Total number } \\
\text { of eggs }(\mathrm{n}=30)\end{array}$ & $\begin{array}{l}\text { Number of eggs } \\
\text { produced per worm }\end{array}$ & $\begin{array}{l}\text { Total number of } \\
\text { eggs hatched }\end{array}$ & $\begin{array}{l}\text { Hatching } \\
\text { percentage }(\%)\end{array}$ \\
\hline $\begin{array}{l}\text { Filterpressmud +cowdung } \\
\text { Filterpressmud + jeevamirtham }\end{array}$ & 270 & $9 \pm 3.0$ & 209 & 77.4 \\
\hline
\end{tabular}

Table 3: Physio-chemical changes in filtermud mixed with jeevamirtham and cowdung treated with earthworm eudrilus eugeniae (Mean \pm SDTukey's test, $\mathrm{p}<0.05$

\begin{tabular}{|c|c|c|c|c|c|c|c|c|c|}
\hline Treatments & $\mathrm{pH}$ & $\mathrm{EC} \mathrm{ds} / \mathrm{m}$ & $\mathrm{N}(\%)$ & $\mathrm{P}(\%)$ & $\mathrm{K}(\%)$ & $\begin{array}{l}\text { Micronutrients } \\
\text { ca }(\%)\end{array}$ & $\operatorname{Mg}(\%)$ & $\mathrm{S}(\%)$ & $\mathrm{C} / \mathrm{N}$ ratio \\
\hline \multirow[t]{2}{*}{ Pressmud@ } & $7.4200 \pm$ & $2.5000 \pm$ & $2.4533 \pm$ & $1.9733 \pm$ & $0.5300 \pm$ & $4.2600 \pm$ & $1.0433 \pm$ & $0.8400 \pm$ & $8.5800 \pm$ \\
\hline & 0.00577 & 0.05774 & 0.01202 & 0.00882 & 0.00577 & 0.01528 & 0.00333 & 0.00577 & 0.00577 \\
\hline Pressmud+cowdung & $7.5233 \pm$ & $1.9167 \pm$ & $3.4767 \pm$ & $2.3467 \pm$ & $0.8767 \pm$ & $4.9267 \pm$ & $1.8233 \pm$ & $1.0567 \pm$ & $9.1367 \pm$ \\
\hline Vermicompost (wc-c1) & $0.00333^{*}$ & $0.00882 *$ & $0.00667 *$ & $0.00882 *$ & $0.00333^{*}$ & $0.00333^{*}$ & $0.00333 *$ & $0.04333 *$ & $0.00882 *$ \\
\hline Pressmud+Jeevamirtham & $7.4967 \pm$ & $2.5500 \pm$ & $4.0733 \pm$ & $2.6600 \pm$ & $0.9867 \pm$ & $5.1333 \pm$ & $1.8767 \pm$ & $1.3433 \pm$ & $14.0400 \pm 0$ \\
\hline Vermicompost (wc-j1) & $0.01667 *$ & $0.02887^{\mathrm{NA}}$ & $0.00333^{*}$ & $0.01528 *$ & $0.00333 *$ & $0.00333^{*}$ & $0.00333 *$ & $0.00333 *$ & $0.01000 *$ \\
\hline
\end{tabular}

$\mathrm{p}=0.05 ; *: 0.04<0.05$-Significant; ${ }^{\text {Na }}: 0.423>0.05$ - Non Significant

Also the $\mathrm{pH}$ of the vermicompost prepared using Jeevamirtham increased from its original value towards neutral. The vermicasts are more neutral in which the worms live and this may be due to the fact that the earthworms neutralize soil as it passes through them by secretions of the calciferous glands secretions from the intestine and also due to ammonia which is excreted. Suthar (2008) reported that there is significant increase in conductivity and $\mathrm{K}$ content in bed soil by the end of vermicomposting process, which might be due to leaching of $\mathrm{K}$ during vermicomposting process, Macronutrients such as nitrogen, phosphorus and also increased significantly in pressmud vermicompost.

In the present study also macronutrient and micronutrient content increased significantly in the vermicompost prepared from pressmud waste due to the supplementation of Jeevamirtham. In the Jeeamirtham supplemeted vermicompost $\mathrm{C} / \mathrm{N}$ ratio was $55.5 \%$ higher than that was present in the cowdung added vermicompost.

\section{DISCUSSION}

Comparatively the higher level of organic content in non worm-worked composts may be due to the increase in their microbial load, which is expected to be less in worm-worked composts (Garg and Kaushik, 2005; Parvaresh et al., 2004; Suthar, 2009).

As far as interaction effects concerned, in compost and vermicompost highest nitrogen content was recorded in T5 which was on par with rest of the treatments. This is because may be due to higher amount of nitrogen in parthenium and cassia (Sharma et al., 2004).

The observed increase in the EC, N, P, K and micronutrients $(\mathrm{Cu}, \mathrm{Zn}, \mathrm{Mg}$ and $\mathrm{Fe}$ ) in all worm worked composts (except in the case of $\mathrm{N}$ in neem leaves compost) showed that the activity of earthworm $E$. eugienae along with microorganisms promoted mineralization process and brought the nutrients to ready to use form for plant growth.

Filter mud has significant fertilizer value but due to prohibitive cost of sludge disposal, it is dumped in open, where it adversely affects the ambient environment. Apart from this, such practices entail wastage of organic and inorganic nutrients present in the filter mud that might be put to good use. The management and nutrient recovery from filter mud carried out in the present work by mixing with Jeevamirtham was very effective. The results showed that during the supplementation of jeevamirtham the nutrient load viz; nitrogen, phosphorus and content was enhanced. The product so obtained can be used in agricultural fields as manure. This study provides a platform for the utilization of Filter mud amended with Jeevamirtham for the process of productive and value added vermicompost manufacture.

\section{CONCLUSION}

Filter pressmud with Jeevamirtham composted using employing Eudrilus eugeniae, showed high manurial value. Hence vermicomposting can be a potential 
ecological engineering process to convert noxious industrial wastes into value-added materials for sustainable agriculture.

\section{REFERENCES}

Arancon, N.Q., C.A. Edwards, R. Atiyeh and J.D. Metzger, 2004. Effects of vermicomposts produced from food waste on the growth and yields of greenhouse peppers. Bioresource Technol., 93: 139-144. DOI: 10.1016/J.BIORTECH.2003.10.015

Bachman, G.R. and J.D. Metzger, 2008. Growth of bedding plants in commercial potting substrate amended with vermicompost. Bioresource Technol., 99: 3155-3161. DOI: 10.1016/J.BIORTECH.2007.05.069

Garg, V.K. and P. Kaushik, 2005. Vermistabilization of textile mill sludge spiked with poultry droppings by epigeic earthworm Eisenia fetida. Bioresource Technol., 96: 1063-1071. DOI: 10.1016/J.BIORTECH.2004.09.003

Gupta, R. and V.K. Garg, 2008. Stabilization of primary sewage sludge during vermicomposting. J. Hazard. Mater, 153: 1023-1030. DOI: 10.1016/J.JHAZMAT.2007.09.055

Gutierrez-Miceli, F.A., B. Moguel-Zamudio, M. AbudArchila, V.F. Gutierrez-Oliva and L. Dendooven, 2008. Sheep manure vermicompost supplemented with a native diazotrophic bacteria and mycorrhizas for maize cultivation. Bioresource Technol., 99: 7020-7026. DOI: 10.1016/J.BIORTECH.2008.01.012

Lakshmi, B.L. and G.S. Vijayalakshmi, 2000. Vermicomposting of sugar factory filter pressmud using African earthworm species E. eugeniae. Pollut. $\quad$ Res., 19: 481-483. http://www.bioline.org.br/pdf?se09030

Lee, K.E., 1992. Some trends opportunities in earthworm research or: Darwin's children. The future of our discipl. Soil Biol. Biochem., 24: 1765-1771.

http://cat.inist.fr/?aModele $=$ afficheN\&cpsidt $=4502$ 376

Parvaresh, A., H. Movahedian and L. Hamidian, 2004. Vermistabilization of municipal wastewater sludge with Eisenia fetida. Iran. J. Environ. Health Sci. Eng., $\quad 1$ : 43-50. http://journals.tums.ac.ir/upload_files/pdf/521.pdf
Prakash, M. and N. Karmegam, 2010. Vermistabilization of pressmud using Perionyx ceylanensis mich. Bioresou. Technol., 101: 84648468. DOI: 10.1016/J.BIORTECH.2010.06.002

Sangwan, P., C.P. Kaushik and V.K. Garg, 2008. Vermiconversion of industrial sludge for recycling the nutrients. Bioresour. Technol., 99: 8699-8704. DOI: 10.1016/J.BIORTECH.2008.04.022

Sharma, N. and M. Madan, 1988. Effects of various organic wastes alone and with earthworms on the total dry matter yield of wheat and maize. Biol. Wastes., 25: 33-40. DOI: 10.1016/02697483(88)90125-5

Sharma, V., K. Kanvar and S.P. Dev, 2004. Efficient recycling of obnoxious weed plants (Lantana camara L.) and Congress grass (Parthenium hysterophorus L.) as organic manure through Vermicomposting. J. Ind. Soc. Soil Sci., 52: 112114.

http://www.indianjournals.com/ijor.aspx?target=ijo r:jisss \& volume $=52 \&$ issue $=1 \&$ article $=021$

Suthar, S., 2008. Bioconversion of post harvest crop residues and cattle shed manure into value-added products using earthworm eudrilus eugeniae kinberg. Ecol. Eng., 32: 206-214. DOI: 10.1016/J.ECOLENG.2007.11.002

Suthar, S., 2009. Vermistabilization of municipal sewage sludge amended with sugarcane trash using epigeic Eisenia fetida (Oligochaeta). J. Haz. Mater., 163: 199-206. DOI: 10.1016/J.JHAZMAT.2008.06.106

Vijayalakshmi, G.S., 2000. Vermicomposting of sugar factory filter pressmud using African earthworm species Eudrilus Eugeniae (Kingberg) with a note on its Physico-Chemical Features. Pollut. Res., 19: 481-483.

http://www.swlf.ait.ac.th/IntlConf/Data/ICSSWM \%20web/FullPaper/Session\%20V\%20B/5_B7\%20 _V.Karthikeyan.pdf

Yadav, A. and V.K. Garg, 2009. Feasibility of nutrient recovery from industrial sludge by vermicomposting technology. J. Hazardous Mater., 168: 262-268. DOI: 10.1016/J.JHAZMAT.2009.02.035

Yadav, K.D., V. Tare and M.M. Ahammed, 2010. Vermicomposting of source-separated human faeces for nutrient recycling. Waste Manage., 30: 50-56. DOI: 10.1016/J.WASMAN.2009.09.034 